九州大学学術情報リポジトリ

Kyushu University Institutional Repository

\title{
Relationship Between Dietary Diversity and Perceived Food Security Status in Indonesia : A Case of Households in The North Luwu of South Sulawes i Province
}

Pipi, Diansari

Laboratory of Agricultural and Farm Management, Graduate School of Bioresource and

Bioenvironmental Science, Kyushu University | Faculty of Agriculture, Hasanuddin University

Nanseki, Teruaki

Faculty of Agriculture, Kyushu University

Chome i, Yosuke

Faculty of Agrisulture, Kyushu University

https://doi.org/10.5109/1467653

出版情報: 九州大学大学院農学研究院紀要. 59 (2)，pp. 399-404，2014-08-29. Faculty of Agriculture, Kyushu University

バージョン :

権利関係 : 


\title{
Relationship Between Dietary Diversity and Perceived Food Security Status in Indonesia - A Case of Households in The North Luwu of South Sulawesi Province -
}

\author{
Diansari PIPI ${ }^{1,2}$, Teruaki NANSEKI ${ }^{3 *}$ and Yosuke CHOMEI $^{3}$
}

\author{
Laboratory of Agricultural and Farm Management, Graduate School of Bioresource and \\ Bioenvironmental Science, Kyushu University, \\ Fukuoka 812-8581, Japan \\ (Received April 25, 2014 and accepted May 12, 2014)
}

\begin{abstract}
The aim of this study is to observe the relationship between the objective and subjective measurement of household food security status in North Luwu in Indonesia. The objective measurement is done by means

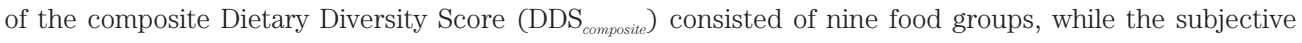
measurement is done using the Subjective Food Security Score (SFSS). Specifically, this study estimated the probability of household for being more food secure due to their dietary diversity status and the com-

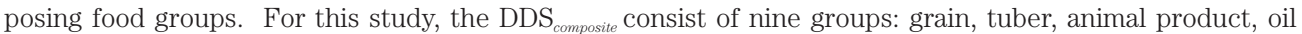
and fat, oily seeds, nuts, sweets, fruits and vegetables, and others. Furthermore, the SFSS has five category of household food security in this measurement: insecure, somewhat insecure, somewhat secure, secure, and highly secure. The descriptive analysis shows that in all $\mathrm{DDS}_{\text {composite }}$ level the perceived food secure category always have the highest percentage. The household head largely regard that their household are in food secure level even thought they only consume two or three kinds of food groups. Another finding is that keeping the tuber food group, in this case sago starch, available in household will make household heads felt more food secure.

From the regression estimation, the $\mathrm{DDS}_{\text {composite }}$ as a composite score of the availability of food groups in a household is found significantly have potency to improve the perceived food security status of the household. Furthermore, among the food groups composing the DDS $_{\text {composite }}$, the existence of tuber, animal products, oily seed, nuts, as well as fruit and vegetables food groups are likely to increase the probability of a household's SFSS being in a better food security category, whereas the sweets food group give a reverse effect.
\end{abstract}

Key words: household food security, objective method, subjective method.

\section{INTRODUCTION}

There is a broad consensus on the need to look at the multi-dimensionality of household food security, including the issue of combining objective and subjective methods used to determine the status of households. Discussions surrounding the need for such a combined approach are well documented and summarized (Bamberger, 2000; Baker, 2000; Coudouel et al. 2001; Hentschel, 1999). However, there is still no consensus over which method is the most successful and it is clear that both have strengths and weaknesses (Mario and Wodon, 2001). Objective approaches, which mostly rely on statistics, provide good results if they involve an appropriate number of samples. However, objective data cannot fully capture causality because of their failure to provide contextual information (Hentschel, 1999). Subjective methods such as close observation or surveys with interviews can explain the economic, socio-cultural or political context of the processes under study. In the other words, subjective assessments provide a better understanding of stakeholders' perceptions and priorities (Baker, 2000).

\footnotetext{
1 Laboratory of Agricultural and Farm Management, Graduate School of Bioresource and Bioenvironmental Science, Kyushu University

2 Faculty of Agriculture, Hasanuddin University, Indonesia

Faculty of Agriculture, Kyushu University, Japan

* Corresponding author: (E-mail: nanseki@agr.kyushu-u.ac.jp)
}

In this study, both objective and subjective approaches have been utilized. For the objective approach, this study used the household food dietary diversity score (DDS). DDS were collected by questionnaire survey. The questionnaire itself is modification of the Food and Nutrition Technical Assistance Project's questionnaire (FANTA) (Swindale and Bilinsky, 2006). The subjective method is achieved via an interview of the household regarding their perceived food security status. DDS has become increasingly popular as an effective food and nutrition indicator, for three basic reasons. First, DDS defines both "food" and "nutrition security" (Ruel, 2003). Secondly, economic theories of demand as well as theories in psychology suggest that individuals will diversify into higher-value, micronutrient-rich foods only when they have satisfied their basic caloric needs. In other words, as poor people become richer, they gravitate away from relatively tasteless, staple foods towards micronutrient-rich foods that impart greater taste and therefore utility. Thirdly, it holds true that the execution of DDS-oriented research is relatively cost-effective (Headey and Ecker, 2012). DDS is an important indicator, as it more accurately reflects dietary quality than, for example, a calorie count; DDS counts the number of different food groups consumed over a given reference period, rather than the number of different foods consumed. Moreover, dietary diversity methods are promising in capturing the diverse nature of Asian diets. The assessment of micronutrients in Asian diets is further 
complicated by the presence of several food components that may interfere with bio-availability, in particular trace minerals (Winichagoon, 2008). The overriding aim of this study is to observe the relationship between the objective and subjective measurement of household food security status in North Luwu in Indonesia. The objective and subjective measurement in this study is by undertaken by means of DDS and a subjective food security score method (SFSS), respectively.

\section{MATERIAL AND METHODS}

The North Luwu district is located about $440 \mathrm{~km}$ from Makassar, the capital city of South Sulawesi province - a major province of the eastern part of Indonesia. The North Luwu district has an area of $7,502.58 \mathrm{~km}^{2}$ and is divided into 11 sub-districts, 167 villages, and 703 neighborhoods. According to the most recent census, there were 290.365 people in 67,328 households living in this district (Central Bureau of Statistics, 2012).

The household sample used in this study was randomly chosen from a household list supplied by the sub- district ward office of 21 villages/neighborhoods located in suburban areas with many households living below the poverty line. The number of households sampled from each village/neighborhood was determined by considering the total population of that village/neighborhood. Following the validation process, 371 households were included in the analytical process.

The determination of the specifics of DDS has been carried out in Pipi et al. (2014). For Indonesia, there are nine food groups that compose DDS: GRAIN (rice, corn, sorghum), TUBER (potato, sweet potato, cassava, sago starch, taro), ANIMAL PRODUCT (fish, meat, dairy product, egg), OIL \& FAT (coconut oil, palm oil), OILY SEEDS (coconut), NUTS (soy bean, peanut, green bean), SWEETS (sugar, palm sugar), FRUITS AND VEGETABLES, and OTHERS (beverages, snacks). Furthermore, Pipi and Nanseki (2014) have explained the way that SFSS is determined. There are five categories of household food security in this measurement: INSECURE (coded: 0); SOMEWHAT INSECURE (coded: 1); SOMEWHAT SECURE (coded: 2); SECURE (coded: 3); and HIGHLY SECURE (coded: 4).

Table 1. Summary of dependent and independent variables

\begin{tabular}{|c|c|c|}
\hline Variables & Unit & Code \\
\hline \multicolumn{3}{|l|}{ Dependent: } \\
\hline - Subjective Food Security Status & - & SFSS \\
\hline \multicolumn{3}{|l|}{ Independent: } \\
\hline - Dietary Diversification Score & Score & $\mathrm{DDS}_{\text {composite }}$ \\
\hline \multicolumn{3}{|c|}{ - Existence of tuber food group (Dummy): } \\
\hline $0=$ Not Exist & - & NO_TUBER \\
\hline $1=$ Exist & - & TUBER \\
\hline \multicolumn{3}{|c|}{ - Existence of animal products food group (Dummy): } \\
\hline $0=$ Not Exist & - & NO_ANIMAL_PROD \\
\hline $1=$ Exist & - & ANIMAL_PROD \\
\hline \multicolumn{3}{|c|}{ - Existence of oil \& fat food group (Dummy): } \\
\hline $0=$ Not Exist & - & NO_OIL \& FAT \\
\hline $1=$ Exist & - & OIL \& FAT \\
\hline \multicolumn{3}{|c|}{ - Existence of oily seed food group (Dummy): } \\
\hline $0=$ Not Exist & - & NO_OILY_SEED \\
\hline $1=$ Exist & - & OILY_SEED \\
\hline \multicolumn{3}{|c|}{ - Existence of nuts food group (Dummy): } \\
\hline $0=$ Not Exist & - & NO_NUTS \\
\hline $1=$ Exist & - & NUTS \\
\hline \multicolumn{3}{|c|}{ - Existence of sweets food group (Dummy): } \\
\hline $0=$ Not Exist & - & NO_SWEETS \\
\hline 1 = Exist & - & SWEETS \\
\hline \multicolumn{3}{|c|}{ - Existence of fruits \& vegetables food group (Dummy): } \\
\hline $0=$ Not Exist & - & NO_FRUIT\&VEGETABLES \\
\hline $1=$ Exist & - & FRUIT\&VEGETABLES \\
\hline \multicolumn{3}{|c|}{ - Existence of others food group (Dummy): } \\
\hline $0=$ Not Exist & - & NO_OTHERS \\
\hline $1=$ Exist & - & OTHERS \\
\hline
\end{tabular}


The SFSS of individual $i$ is assumed to be explained either by $\mathrm{DDS}_{\text {composit }}$ or by the food groups that compose the DDS ( $\left.\operatorname{DDS}_{\text {food groups }}\right)$. $\operatorname{DDS}_{\text {composit }}$ is diversity score of a household (continuous variable), while the DDS food groups is the existence of each food group in a household (dummy variables).

$$
\begin{aligned}
\mathrm{SFSS}_{i}= & f\left(\mathrm{DDS}_{\text {composite }}\right) \quad \ldots \ldots \ldots \ldots \ldots \ldots \ldots \ldots \ldots \\
\mathrm{SFSS}_{i}= & f\left(\mathrm{DDS}_{\text {food groups }}\right) \\
= & f(\mathrm{TUBER}, \mathrm{ANIMAL} \text { PRODUCTS } \\
& \quad \text { OIL\&FAT, OILY SEED, NUTS, SWEETS, } \\
& \quad \text { FRUIT\&VEGETABLES, OTHERS ... }
\end{aligned}
$$

In reality, a household head's perception of their food security status is dynamic. However, for simplicity's sake and owing to the constraints of data availability, we adopted a static framework.

Suppose that the perceived household food security status, $\mathrm{SFSS}_{i}$, is a linear function of $K$ factors, with values for individual $i$ described by $\mathrm{X}_{i k}, k=1, \ldots, K$. Then, the structural model is as follows:

$$
\operatorname{SFSS}_{i}=\sum_{k=1}^{k} \beta_{k} X_{i k}+\varepsilon_{i}
$$

Where $\beta_{k}$ is the coefficient associated with the $k$-th variable, and $\varepsilon_{i}$ is an error term. The error term is assumed to have a standard logistic distribution with a mean of zero and a variance of $\pi^{2} / 3$. SFSS $_{i}$ is the latent variable or unobserved dependent variable.

There is a number of different modeling approaches associated with ordinal dependent variable analysis, including cumulative, stage, and adjacent approaches (Fullerton, 2009; Menard, 1995). The data taken as well as the type of comparison that is required between the categories determines which approach is appropriate for the study. Since the SFSS status follows an ordinal scale, but represents an underlying continuous measure, Fullerton (2009) recommends using the cumulative approach. Traditionally, the cumulative approach represents the classic ordered Logit model approach. For this model:

$$
\operatorname{SFSS}_{i}^{*}=\beta_{i}^{\prime} X_{i k}+\varepsilon_{i}
$$

Where $S F S S_{i}^{*}$ is the underlying latent variable that indexes the SFSS. The latent variable exhibits itself in ordinal categories, coded as $J=0,1,2,3$, and 4 . Therefore, the observed response in category $J$ when the underlying continuous response falls in the $j$-th interval is as follows:

$$
\begin{array}{lll}
\text { SFSS }=0 & \text { if } & \text { SFSS }^{*} \leq \delta_{1} \\
\text { SFSS }=1 & \text { if } & \delta_{1}<\text { SFSS }^{*} \leq \delta_{2} \\
\text { SFSS }=2 & \text { if } & \delta_{2}<\text { SFSS }^{*} \leq \delta_{3} \\
\text { SFSS }=3 & \text { if } & \delta_{3}<\text { SFSS }^{*} \leq \delta_{4} \\
\text { SFSS }=4 & \text { if } & \delta_{4} \leq \text { SFSS }^{*}
\end{array}
$$

Where $\delta_{j}(j=0,1,2,3,4)$ are the unobservable cutoff point (threshold) parameters that will be estimated together with other parameter in the model. For the purpose of statistical analysis, the standard for significance is $\mathrm{P}<0.05$.

Table 1 summarizes the dependent and independent variables. For the equation (1), the independent variable is only the $\operatorname{DDS}_{\text {composite }}$. For the equation (2), all variables are dummy variables that compare the effect of the existence/availability or absence of food groups in household, on the perceived household food security of the household head. Since the GRAIN food group is available in every household sample, this group is omitted from the calculation.

\section{RESULT AND DISCUSSION}

The descriptive relationship between perceived household food security and composite dietary pattern of the household is presented in Table 2. It obvious by analyzing the table that although to some extent, there

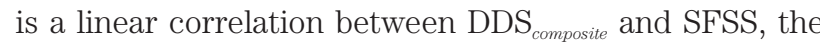
correlation between those two methods is weak and tends to be non-linear in its pattern. A similar correlation between quantitative-objective and qualitative-subjective methods is also found in other studies. Lorenzana and Sanjur (1991) found a correlation between energy availability and self-perceived HFS scale, while Magitto et al. (2006) concluded that calorie consumption, dietary diversity and anthropometry have at best a weak correlation with subjective perceptions of food consumption. Coates et al. (2003) find a similar lack of association between anthropometric measures and subjective indicators in their Bangladesh study.

From Table 2, we can see that most of households serve 5 to 7 food groups and in all DDS composite $_{\text {levels the }}$ food SECURE category of SFSS always represents the highest percentage. It means that in general the perceived household food security status in the sample area is at a SECURE level. It also can be interpreted that most household heads regard that their household are in a food SECURE level even though they only consume two (53\%) or three (79\%) kinds of food groups. This finding is important because it may disguise the real state of the household food security status. It seems that there is still some misunderstanding over the concept of dietary balance, as the household head may think that having rice (GRAIN) plus one or two other food groups, which is a very common situation in this area, is enough and safe for their household. On the other hand, all households who have a DDS of 9 fall in food SECURE (41\%) or HIGHY SECURE (51\%) categories. It is obvious that the heads, whose household consumes 9 groups of food, are mostly very sure that their households are in the best condition, in terms of their food security status.

Figure 1 is taken from previous research (Pipi et al., 2014). It is clear that after rice in the GRAIN food group, the most available food groups that are prepared by the households with a DDS of 2 and 3 are ANIMAL PRODUCTS (90\%) and FRUITS \& VEGETABLES (86\%). Using the same way of thinking, it can be also said that to households with a DDS of $4,5,6$, or 7 , we might add 
Table 2. Perceived household food security and dietary diversification score cross tabulation (N=371 Households)

\begin{tabular}{|c|c|c|c|c|c|c|c|c|}
\hline \multirow[b]{2}{*}{ Category } & \multirow[b]{2}{*}{$\mathrm{DDS}_{\text {composite }}$} & \multicolumn{5}{|c|}{ SFSS } & \multirow{2}{*}{\multicolumn{2}{|c|}{ Total }} \\
\hline & & Insecure & $\begin{array}{l}\text { Somewhat } \\
\text { Insecure }\end{array}$ & $\begin{array}{l}\text { Somewhat } \\
\text { Secure }\end{array}$ & Secure & Highly Secure & & \\
\hline Insecure & 2 & $4(31 \%)$ & $1(8 \%)$ & $1(8 \%)$ & $7(53 \%)$ & - & 13 & $(100 \%)$ \\
\hline Somewhat Insecure & 3 & $1(5 \%)$ & - & $2(16 \%)$ & $16(79 \%)$ & - & 19 & $(100 \%)$ \\
\hline Somewhat Secure & 4 & - & $10(20 \%)$ & $5(10 \%)$ & $35(70 \%)$ & - & 50 & $(100 \%)$ \\
\hline \multirow{3}{*}{ Secure } & 5 & - & $9(10 \%)$ & $26(31 \%)$ & $46(59 \%)$ & - & 81 & $(100 \%)$ \\
\hline & 6 & - & $17(26 \%)$ & $19(29 \%)$ & $29(45 \%)$ & - & 65 & $(100 \%)$ \\
\hline & 7 & - & $4(4 \%)$ & $27(30 \%)$ & $58(66 \%)$ & - & 89 & $(100 \%)$ \\
\hline \multirow{2}{*}{ Highly Secure } & 8 & - & - & $7(19 \%)$ & $25(68 \%)$ & $5(13 \%)$ & 37 & $(100 \%)$ \\
\hline & 9 & - & - & - & $7(41 \%)$ & $10(59 \%)$ & 17 & $(100 \%)$ \\
\hline Total & & $5(1.3 \%)$ & $41(10.8 \%)$ & $87(23.5 \%)$ & $223(60.4 \%)$ & $15(4 \%)$ & 371 & $(100 \%)$ \\
\hline
\end{tabular}

Source: Original field survey, March 2012

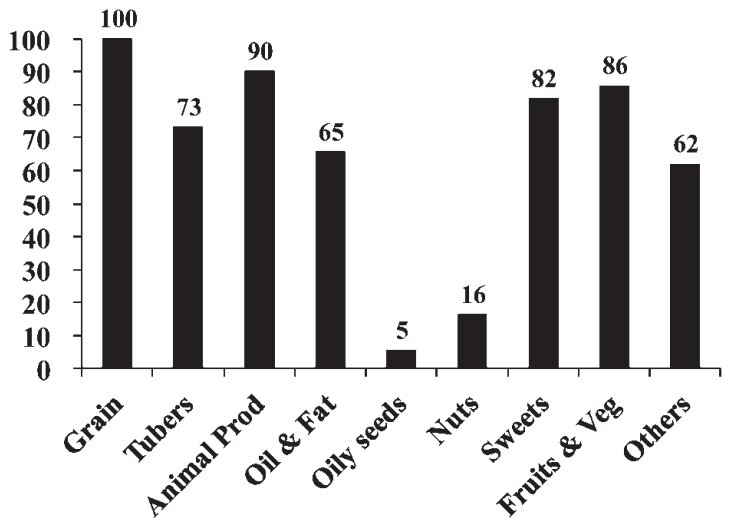

Fig. 1. Distribution of food groups consumed by the household respondents (Pipi et al., 2014)

Note: N=371 Respondent

their prepared food groups of SWEETS (82\%), TUBERS (73\%), OIL \& FAT (65\%), and OTHERS (62\%) food groups, respectively. However, considering the income class of the households, those additional food groups might become a burden for some of the households. This situation may explain the perceived household food security anomaly in which the percentage of households with a DDS of $4,5,6$, and 7 that are in a SECURE or better category is less than in households with a DDS of 2 , 3,8 and 9 .

In general, when it is read independently within the food group, Figure 2 only show the difference in household food security distribution categories based on the absence or existence of any given food group in sample households. Apart from the TUBER food group, in all food groups, when those foods are absent, the percentage of households that are in a food SECURE or better category is more than $50 \%$. Considering that based on their dietary diversity score, the sample households were in a lower food security status (Pipi and Nanseki, 2014), that percentage probably represents the household head's own perception where they might think that the absence of those food groups will not affect their house- hold food situation to a great extent. It is another case altogether when considering the TUBER food group. In the households where this food group is absent, those that fall under food SECURE or higher categories only contribute $42 \%$. This percentage is almost a half lower than those where this food group is present (73\%). Those numbers imply that household heads felt more food secure when they possess tuber in their household. This situation is in line with the background of this area, as sago starch, which is a form of tuber, is the most important historical and cultural food after rice. Traditionally, people in this area consume sago starch product as their lunch, and rice for their breakfast and dinner. Therefore, in other words, in terms of the household heads' perception, being able to consume sago starch (TUBER) boosts their household food security status.

When Figure 2 is looked at alongside Figure 1, it can be inferred that the OILY SEED food group, which mainly consists of coconut and its derivates, is only possessed by the food SECURE or HIGHLY FOOD SECURE households. That is confirming the low percentage of this food group in Figure 2. We believe that the same situation also applies for the NUTS food group where there are no households that fall in the 'food insecure category' that keep this food group for serving in their households. That situation is completely expected as those two food group are relatively expensive and only be used as an additional ingredient to augment another food group (e.g. ANIMAL PRODUCT or FRUITS \& VEGETABLES).

When the composite score of $\mathrm{DDS}_{\text {composite }}$ predicts the SFSS, the odd ratio from the ordered LOGIT analysis is 1.3 (Table 3). Having the chi-square likelihood ratio of 18.5 , with a p-value of $<0.0001$, the model tell us that for a one-unit increase in DDS $_{\text {composite, }}$ the odds ratio of the HIGHLY SECURE category is 1.3 times greater than that of the other categories combined, given that the other variables in the model are held constant. The same increase (1.3 times) is found between SECURE category and the other combined categories. In a simple word, the dietary diversity in a household has the poten- 


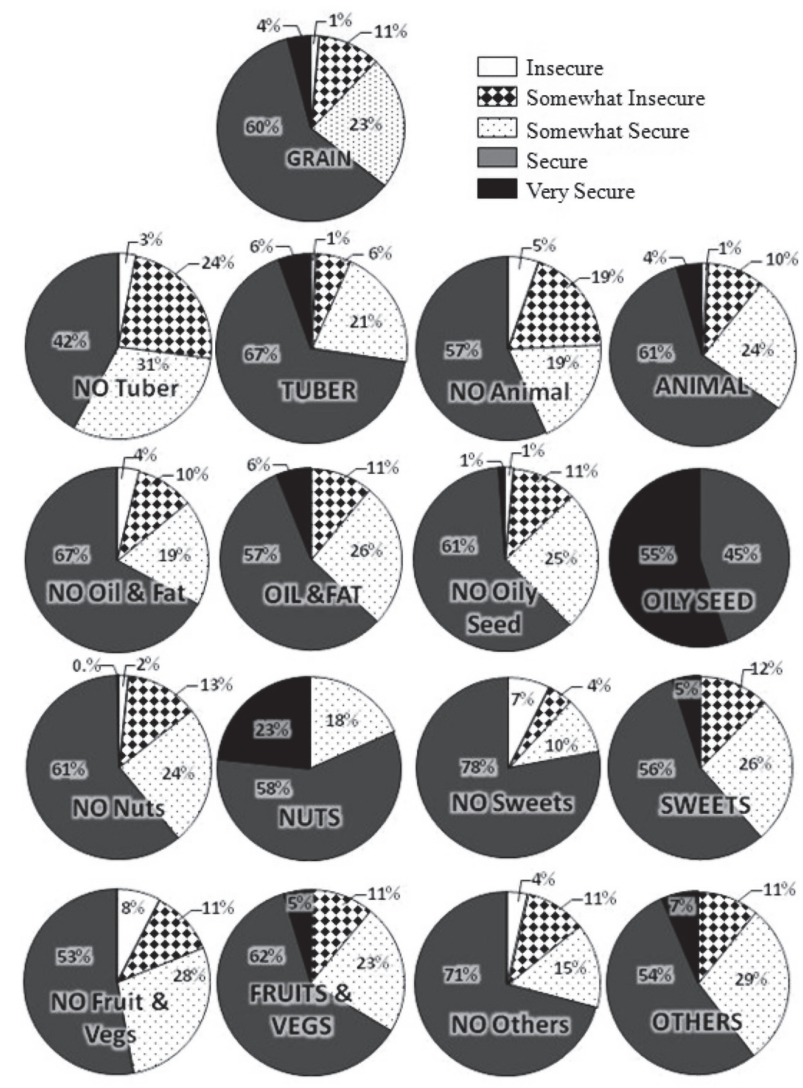

Fig. 2. Perceived household food security distribution among the food groups.

Table 3. Ordered logistic regression analysis results between SFSS and DDS

\begin{tabular}{rccc}
\hline Odds Ratio & Std. Err & $\mathrm{P}>|\mathrm{z}|$ \\
\hline $\mathrm{DDS}_{\text {composite }}$ & $1.342^{* * *}$ & 0.812 & 0.000 \\
\hline Note: ${ }^{* * *}$ significant at $P<1 \%$ & &
\end{tabular}

Table 4. Ordered logistic regression analysis results between SFSS and DDS food__roup $_{\text {f }}$

\begin{tabular}{lccc}
\hline & Odds Ratio & Std. Err & $\mathrm{P}>|\mathrm{z}|$ \\
\hline TUBER & $3.785^{* * *}$ & 0.910 & 0.000 \\
ANIMAL_PROD & 1.926 & 0.714 & 0.077 \\
OIL\&FAT & 0.673 & 0.181 & 0.142 \\
OILY_SEED & $4.693^{* * *}$ & 3.849 & 0.000 \\
NUTS & $2.827^{*}$ & 1.141 & 0.010 \\
SWEETS & $0.437^{*}$ & 0.160 & 0.024 \\
FRUIT\&VEGETABLE & $2.467^{* * *}$ & 0.800 & 0.005 \\
OTHERS & 0.763 & 0.215 & 0.336 \\
\hline
\end{tabular}

Note: ***significant at $P<1 \%$; **significant at $P<5 \%$ tial to influence the perceived food security status of the household in a positive direction. When the SFSS is predicted using each food group that comprises the DDS $\left(\mathrm{DDS}_{\text {food_group }}\right)$ then a more comprehensive result is available, as is shown in Table 4 below.

From the same analysis of the result in Table 3, the chi-square likelihood ratio of 120.8 , with a p-value of $<0.0001$, tells us that the model as a whole is statistically significant. Thus, the odds ratio coefficients imply that the existence of TUBER, OILY SEED, NUTS, as well as FRUIT AND VEGETABLES food groups in the household are likely to increase the probability of a household's SFSS being in a better food security category. On the other hand, the SWEETS food group is likely to increase the probability of a household's SFSS being in a worse category. Specifically, when the TUBER food group is available in household, the odds ratio of the HIGHLY SECURE category is 3.8 times greater than that of the other categories combined, given that the other variables in the model are held constant. When highlighting SECURE category, it will be subject to the same increase, 3.8 times, is found between SECURE category and the combined other categories. Likewise, the odds ratio of the HIGHLY SECURE category is 4.7, 2.8, and 2.5 times greater than the other categories combined if OILY SEED, NUTS, as well as FRUIT AND VEGETABLES are prepared in the household, respectively. Furthermore, when the SWEETS food group is prepared in households, the odds ratio of the SECURE category versus the other categories combined is 0.4 times less, given that the other variables in the model are held constant.

\section{CONCLUSION}

In this study, we have observed the relationship between the objective and subjective measurement of household food security status in North Luwu. The objective measurement was achieved by means both of the composite Dietary Diversity Score (DDS composite $_{\text {) }}$ and food groups in the Dietary Diversity Score $\left(\mathrm{DDS}_{\text {food_groups }}\right)$, while the subjective measurement was carried out using the Subjective Food Security Score (SFSS). Specifically, this study estimated the probability of households being more or less food secure as a result of their dietary diversity status and their available food groups.

The descriptive analysis showed that in general, the correlation between DDS $_{\text {composite }}$ and SFSS was weak and tended to be non-linear in pattern. In all DDS composite $_{\text {lev- }}$ els the perceived food SECURE category always had the highest percentage. However, what is a more important finding from this study was that household heads largely regarded their households to be in a food secure level even though they only consumed food from only two or three of the food groups. This finding is important because it implies that there is still a misunderstanding about the concept of the kind of dietary balance needed to support the food security of a household. Another finding from the descriptive analysis is that keeping the TUBER food group, in this case sago starch, available in a household will make household heads feel more food 
secure, a perceived impact which is similar with a household that keep a OILY_SEED food group for daily use.

From the regression estimation, the DDS composite $_{\text {as a }}$ composite score of the availability of food groups in a household was found to significantly improve the perceived food security status of the household. Furthermore, among the food groups composing the DDS $_{\text {food_groups, }}$, the existence of TUBER, OILY SEED, NUTS, as well as FRUIT \& VEGETABLES food groups are likely to increase the probability of a household's SFSS being in a better food security category, whereas the SWEETS food group gave a reverse effect.

There are at least three major implication of this research. Firstly, enlightenment as to the important of dietary balance has to be rectified and efforts in this direction need intensifying. Reflecting on the results of the previous study, the concept of dietary balance should be taught both in formal as well as in non-formal educational institutions. Secondly, considering the dietary history of the area, local stakeholders must encourage households to utilize sago starch more than before and in a more varied form so as well as enhancing the household's food security status, it also can lead to the substitution of rice as a staple food in general. Lastly, a reduction in the consumption of food from the SWEETS group must be started not only in order to achieve a better household food security status but also to yield healthier household members.

\section{REFERENCES}

Baker, J. 2000 Evaluating the Impact of Development Projects on Poverty. World Bank, Washington, DC

Bamberger, M. 2000 Integrating Quantitative and Qualitative Research in Development Projects. The World Bank, Washington, DC

Central Bureau of Statistics 2012 South Sulawesi in figures 2011. BPS Press (In Indonesian)

Coates, J., Webb, P. and Houser R. 2003 Measuring Food Insecurity: Going Beyond Indicators of Income and
Anthropometry. Food and Nutrition Technical Assistance Project. Academy for Educational Development, Washington, DC

Coudouel, A., Hentschel, J. and Wodon, Q. 2001 Poverty Measurement and Analysis, In "Poverty Reduction Strategies Source Book" ed. by J. Klugman, World Bank, Washington, DC

Fullerton, A 2009 A Conceptual Framework for Ordered Logistic Regression Models. Sociological Methods and Research, 38(2): 306-347

Headey, D., Ecker, O. 2012 Improving the Measurement of Food Security. International Food Policy Research Institute, Discussing Paper, No. 01225, pp. 1-25

Hentschel, J. 1999 Contextuality and Data Collection Methods: A Framework and Application to Health Service Utilization. Joumal of Development Studies, 35(4): 64-94

Lorenzana, P. A. and Sanjur, D. 1999 Abbreviated Measures of Food Sufficiency Validly Estimate the Food Security Level of Poor Households: Measuring Household Food Security. Journal of Nutrition, 129(3): 687-692

Mario, E. G. and Wodon, Q. 2001 Measurement and Meaning, Combining Qualitative and Quantitative Methods for the Analysis of Poverty and Social Exclusion in Latin America. World Bank, Technical Paper no. 518

Menard, S. 1995 Applied Logistic Regression Analysis. Sage Publication

Migotto, M., Davis, B., Carletto, G. and Beegle, K. 2006 Measuring Food Security Using Respondents' Perception of Food Consumption Adequacy. World Institute Development Economic Research, Research Paper No. 2006/88

Pipi, D., Nanseki, T., and Takeuchi, S. 2014 The Determinants of Food Security in Indonesia - A Case Of Households in The North Luwu of South Sulawesi Province, Journal of Rural Economics, 16: 41-48

Pipi, D. and Nanseki, T. 2014 Perceived food security status: A case study of households in North Luwu, Indonesia. Journal of Nutrition and Food Science. (Under Revision).

Ruel, M. 2003. Operationalizing Dietary Diversity: A Review of Measurement Issues and Research Priorities, Journal of Nutrition, 133(11): 3911-3926

Swindale, A., Bilinsky, P. 2006 Household Dietary Diversity Score (HDDS) for Measurement of Household Food Access: Indicator Guide. FANTA-USAID, Ver. 2

Winichagoon, P. 2008 Limitations and Resolutions for Dietary Assessment of Micronutrient Intakes. Asia Pacific Journal of Clinical Nutrition, 17(S1): 296-298 